\title{
Unexpected Evergreen Expansion in the Siberian Forest under Warming Hiatus ${ }^{\mathscr{D}}$
}

\author{
YONGLI HE \\ Key Laboratory for Semi-Arid Climate Change of the Ministry of Education, College of \\ Atmospheric Sciences, Lanzhou University, Lanzhou, China, and Department \\ of Environmental Sciences, University of Virginia, Charlottesville, Virginia \\ JIANPING HUANG \\ Key Laboratory for Semi-Arid Climate Change of the Ministry of Education, \\ College of Atmospheric Sciences, Lanzhou University, Lanzhou, China \\ HERMAN HENRY SHUGART \\ Department of Environmental Sciences, University of Virginia, Charlottesville, Virginia \\ XiAODAN GUAN \\ Key Laboratory for Semi-Arid Climate Change of the Ministry of Education, \\ College of Atmospheric Sciences, Lanzhou University, Lanzhou, China \\ BIN WANG AND KAILIANG Yu \\ Department of Environmental Sciences, University of Virginia, Charlottesville, Virginia
}

(Manuscript received 5 March 2016, in final form 11 March 2017)

\begin{abstract}
Siberia has experienced a pronounced warming over the past several decades, which has induced an increase in the extent of evergreen conifer forest. However, the potential slowing of the trend of increasing surface air temperature (SAT) has produced intense debate since the late 1990s. During this warming hiatus, the Siberian region experienced a significant cooling during the winter season around 10 times that of the Northern Hemisphere $(\mathrm{NH})$ as a whole. This potentially stresses evergreen conifer forests because cooler winters can cause cold-temperature damage and, hence, increase the mortality of young evergreen conifer forests. In this study, the response of Siberian forest composition during the warming hiatus was investigated using satellite observations coupled with model simulations. Observations indicated that from 2001 to 2012, the apparent area of evergreen conifer forest has increased by $10 \%$, while that of the deciduous conifer forest has decreased by $40 \%$. The transition from deciduous to evergreen conifer forest usually occurs through mixed forest or woody savannas as a buffer. To verify the response of evergreen conifer forest, model experiments were performed using an individual-based forest model. Hysteresis of forest change seen in the model simulations indicates that changes in forest composition dynamics under temperature oscillations induced by internal climate variability may not reverse this composition change. As a result, the evergreen conifer forest expansion under climate warming is expected to be a continuing process despite the occurrence of a warming hiatus, exerting far-reaching implications for climate-changeinduced albedo shifts in the Siberian forest.
\end{abstract}

Supplemental information related to this paper is available at the Journals Online website: http://dx.doi.org/10.1175/ JCLI-D-16-0196.s1.

Corresponding author: Dr. Jianping Huang, hjp@lzu.edu.cn

\section{Introduction}

Through physical and biological processes, the Siberian boreal forest plays an important role in regulating regional (and even global) carbon and hydrologic cycles, atmospheric composition, and climate feedbacks (Bonan 2008). 
Both simulations and observations show that the mid- to high latitudes of the Northern Hemisphere have experienced the most enhanced warming in recent decades (Wallace et al. 2012; Huang et al. 2012). This warming is projected to continue during the twenty-first century (Collins et al. 2013). Many studies have focused on the underlying mechanisms of enhanced warming in the semiarid area in East Asia (Wang et al. 2014; Huang et al. 2015a,b), but there are few comparable studies in Siberia. He et al. (2014) found that the feedback between land-sea thermal contrast decreases and blocking decreasing can accelerate the warming process during warming periods. The Russian boreal forest, a tremendous repository of terrestrial organic carbon, is located in this climatically sensitive region. Global climate change significantly affects forest distribution, composition, structure, and function through changes in water-use efficiency, temperature, and length of the growing season or by altering the disturbance regimes (e.g., fires and permafrost) (Piao et al. 2007; Schwartz et al. 2006; Flannigan et al. 2000). Field observations in Siberia by Kharuk et al. (2005b, 2007) show a shift from deciduous conifer forests dominated by larch (Larix spp.) to evergreen conifer forests at both elevational and latitudinal forest transitions across Siberia. Particularly in winter, this conversion to evergreen conifer forest produces a decrease in albedo relative to the larch forest and has the capacity to induce additional local warming (Kharuk et al. 2005b, 1992; Shuman et al. 2011; Bonan 2008). This positive albedo-temperature-vegetation feedback can further accelerate the compositional changes in the forest. Moreover, the feedback may accelerate the permafrost thawing induced by climate warming and release a large amount of carbon dioxide and methane (MacDougall et al. 2012). This raises concerns that such changes could shift Earth's climate to a qualitatively different state (Lenton et al. 2008). Certainly, it is important to understand the mechanism of the response of this forest composition to climate variability.

The recent changes in the land surface air temperature (SAT) are neither linear nor uniform (Ji et al. 2014). There has been an apparent pause in the increase of global-mean surface air temperature since the turn of this century, dominated by a winter cooling trend over Eurasia (Meehl et al. 2011; Cohen et al. 2012b; Trenberth and Fasullo 2013; Chen and Tung 2014; Roberts et al. 2015). There have been some studies on understanding the mechanisms behind this phenomenon, notably the eastern equatorial Pacific cooling (Kosaka and Xie 2013) associated with the strengthening of the trade winds (England et al. 2014), the Pacific decadal oscillation (PDO) (Trenberth and Fasullo 2013; Meehl et al. 2014; Steinman et al. 2015), and the deepocean heat uptake in the Atlantic and the Southern
Oceans (Chen and Tung 2014). However, the impact of El Niño-Southern Oscillation (ENSO) on mid- to highlatitude surface temperature may be suppressed because of the negative phase of PDO during the recent decade (Wang et al. 2014).

Wallace et al. (2012) proposed a dynamical adjustment method to divide the raw temperature data into two parts, the dynamically induced temperature (DIT) and radiatively forced temperature (RFT). The DIT component was induced by the atmospheric circulation pattern and the RFT component was considered a result of the buildup of greenhouse gases (GHGs), stratospheric ozone depletion, volcanic eruption, aerosol emission, and local anthropogenic forcing. Guan et al. (2015a,b) confirmed from raw SAT data that the dynamically induced and radiatively forced SAT changes had opposite contributions to the SAT warming hiatus. By correcting the errors from commercial ships and drifting surface buoys, a recent study (Karl et al. 2015) indicates that the global warming trend over the first 15 years of the twenty-first century is at least as great as the trend of the last half of the twentieth century. A comparison between the old uncorrected and new corrected datasets is further investigated below to verify the detailed midlatitude cooling trend.

An apparent transition from deciduous conifer forest to evergreen conifer forest has been both observed in central Siberia (Kharuk et al. 2007, 2005b) and projected by model simulations in response to increasing temperatures (Shuman et al. 2011). However, the evidence of the transition across the large-scale region is still lacking. Therefore, one of the goals of this paper is to provide such evidence. Besides, the earlier work generally assumed the linear increasing changes of temperature; few studies consider the response of evergreen conifers to temperature oscillations. During the accelerated warming period (1980-2000), warmer winters could protect the young evergreen conifers from cold-temperature damage and confer a competitive advantage through a reduction in the growing-season mortality of evergreen conifers (Kharuk et al. 2007; Kullman 2007). The question remains if enhanced winter cooling during the warming hiatus could change evergreen conifer trees' competitive advantage and reverse current directions of land-cover changes. If the warming hiatus and cooling winter conditions persist for another decade (Chen and Tung 2014; Li et al. 2013), will this be sufficient to halt or even reverse the expansion of evergreen conifer forests? Using historical landcover data derived from the Moderate Resolution Imaging Spectroradiometer (MODIS) and the individualbased forest gap model University of Virginia Forest Model Enhanced (UVAFME), this paper investigates 
TABLE 1. The detailed information of data sources used here.

\begin{tabular}{|c|c|c|c|c|}
\hline Dataset & Version & Resolution & Cover time & Download website \\
\hline CRU TS & 3.21 & $0.05^{\circ}$ & 1901-2012 & http://browse.ceda.ac.uk/browse/badc/cru/data/cru_ts/cru_ts_3.22/data/ \\
\hline GISS & - & $2^{\circ}$ & $1880-2015$ & http://data.giss.nasa.gov/gistemp/ \\
\hline GHCN & 3.2 .2 & $5^{\circ}$ & 1880-2015 & ftp://ftp.ncdc.noaa.gov/pub/data/ghcn/v3/grid/ \\
\hline NCEI & - & $5^{\circ}$ & $1871-2014$ & ftp://ftp.ncdc.noaa.gov/pub/data/scpub201506 \\
\hline MCD12Q1 & 051 & $500 \mathrm{~m}$ & $2001-12$ & https://lpdaac.usgs.gov/dataset_discovery/modis/modis_products_table/mcd12q1 \\
\hline MCD45A1 & 051 & $500 \mathrm{~m}$ & $2000-15$ & https://lpdaac.usgs.gov/dataset_discovery/modis/modis_products_table/mcd45a1 \\
\hline GFED & $4 \mathrm{~s}$ & $0.25^{\circ}$ & 1997-2014 & http://www.falw.vu/ gwerf/GFED/GFED4/ \\
\hline MOD44B & 051 & $250 \mathrm{~m}$ & $2000-15$ & https://lpdaac.usgs.gov/dataset_discovery/modis/modis_products_table/mod44b \\
\hline GlobCover & 2009 & $300 \mathrm{~m}$ & 2009 & http://due.esrin.esa.int/page_globcover.php \\
\hline $\begin{array}{l}\text { Global forest } \\
\text { change }\end{array}$ & 1.2 & $30 \mathrm{~m}$ & 2000-14 & $\begin{array}{l}\text { https://earthenginepartners.appspot.com/science-2013-global-forest/download_ } \\
\text { v1.2.html }\end{array}$ \\
\hline
\end{tabular}

whether, under a warming hiatus with winter cooling, one should expect a halt or even a reversal of the transition to evergreen conifer forest in Siberia.

This paper is arranged as follows: Section 2 describes the data. Section 3 shows the details of investigation into the midlatitude cooling trend in Siberia during the warming hiatus. Section 4 investigates the changes of Siberian forest composition during this warming hiatus from satellite observations. Section 5 verifies the response of Siberian forest to warming hiatus using the individual-based forest model UVAFME. Finally, section 6 provides a summary and discussion.

\section{Data and methods}

This study focused on the region $\left(45^{\circ}-65^{\circ} \mathrm{N}, 55^{\circ}-95^{\circ} \mathrm{E}\right)$ in central Siberia (Fig. 2; described in greater detail below), which is at the center of warming hiatus and cooling winter temperature trends and represented by the current natural range of evergreen and deciduous conifers forests. The monthly mean precipitation, surface air temperature, and maximum and minimum temperature were obtained from the Climatic Research Unit (CRU) Time Series (TS), version 3.21, of the University of East Anglia (Harris et al. 2014). The maximum and minimum temperatures provided the input data of the forest model UVAFME. These data covered the period from 1901 to 2012 and had a high spatial resolution $\left(0.5^{\circ} \times 0.5^{\circ}\right)$. Monthly SAT (from 1880 to the present) from the Goddard Institute for Space Studies (GISS; $2^{\circ} \times 2^{\circ}$ resolution) and Global Historical Climatology Network (GHCN), version $3.22\left(5^{\circ} \times 5^{\circ}\right.$ resolution), were also used to verify the warming hiatus. The U.S. National Centers for Environmental Information (NCEI; Karl et al. 2015; Jones 2016) gridded monthly temperature anomaly dataset was used to investigate the midlatitude cooling trend, with an updated version adjusted by bias corrections. Annual global land-cover data and their assessment accuracy for the period of 2001-12 were obtained from the MODIS landcover type product MCD12Q1 (Friedl et al. 2010). Land-cover type (LC) is an annual MCD12Q1 product with a spatial resolution of $500 \mathrm{~m}$, which identifies the dominant land-cover type using a supervised classification approach. The primary land-cover scheme used in this study identifies 17 land-cover classes defined by the International Geosphere-Biosphere Programme (IGBP), including 11 natural vegetation classes, 3 developed and mosaicked land classes, and 3 nonvegetated land classes. For the study we also utilized the MODIS monthly burned area product (MCD45A1) (Roy et al. 2008) and vegetation continuous field (MOD44B) (Townshend et al. 2011). The fourth version of the Global Fire Emissions Database (GFED4s) was used based on the updated version from Van Der Werf et al. (2010). The details of these data are provided in Table 1. Among the UVAFME model input data, both site parameters and species parameters for the 100 sites were obtained from the weather station or from other observations as described in Shuman et al. (2011).

The GlobCover 2009 land-cover dataset was used to compare with the MODIS land-cover dataset and downloaded from the ESA website (http://due.esrin.esa. int/page_globcover.php). When compared with MODIS, GlobCover 2009 was resampled to $500-\mathrm{m}$ resolution by the nearest method. A global forest changes dataset was developed by Hansen et al. (2013), including global tree cover extent, loss, and gain from 2000 to 2012 at a spatial resolution of $30 \mathrm{~m}$, based on Landsat data. Forest loss was defined as a stand-replacement disturbance or the complete removal of tree cover canopy at the Landsat pixel scale. Forest gain was defined as the inverse of loss, or the establishment of tree canopy from a nonforest state. They also opened two high-resolution reference images from Landsat cloudfree composite images with high resolution $(30 \mathrm{~m})$ in circa 2000 and 2014, which provided us an opportunity to investigate the changes of evergreen forest by 

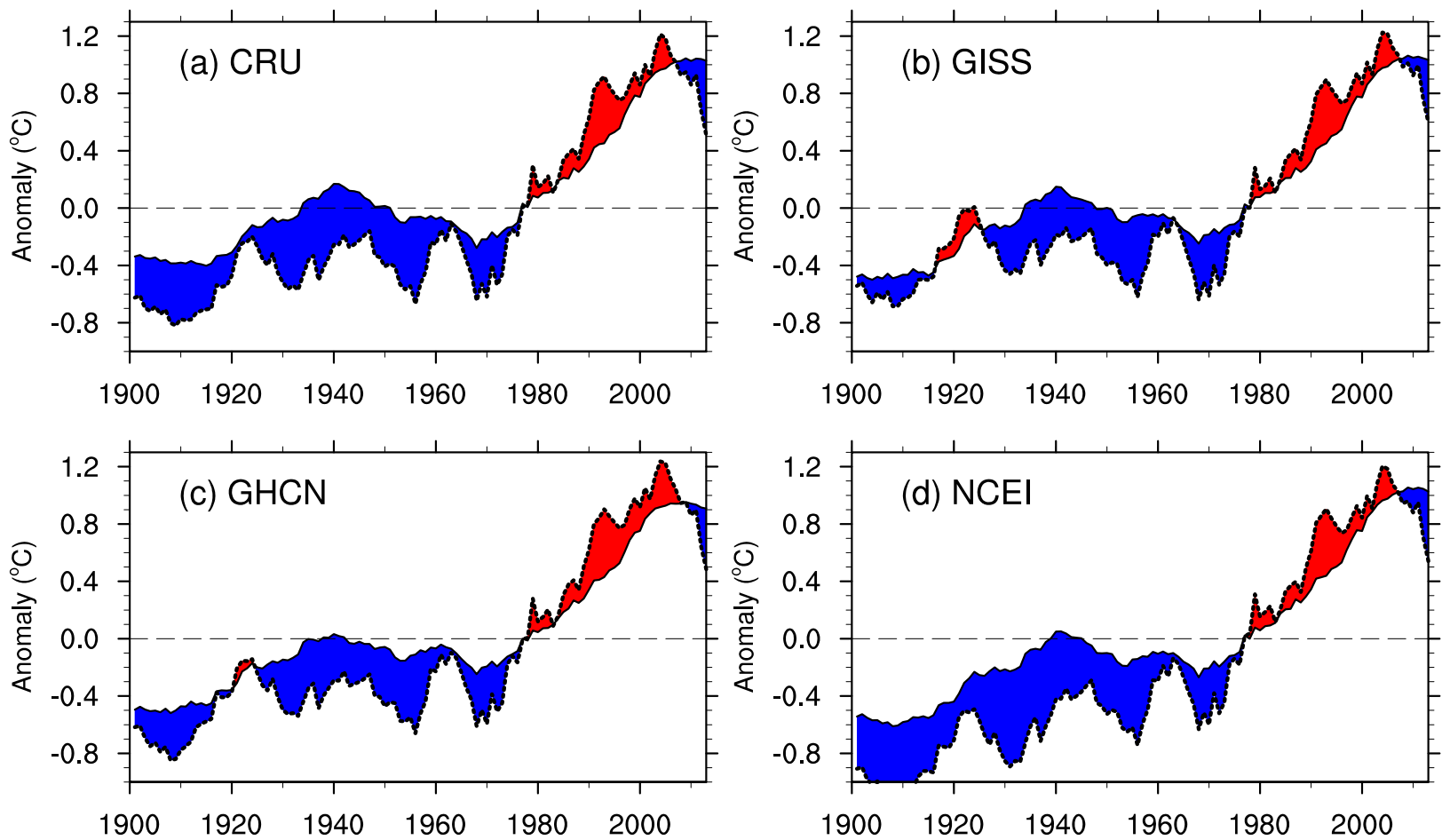

FIG. 1. Annual average SAT anomalies for the NH (solid lines) and Siberia (dashed lines) relative to the 1961-90 climatology from the four different datasets (GISS, GHCN, CRU, and corrected NCEI). The values are 9-yr Gaussian-type filtered. The areas where temperature in Siberia is higher than NH are filled in red; the areas of cooler temperatures are filled in blue.

high-resolution images. The reference composite imagery is median observations from a set of quality assessed growing-season observations in four spectral bands, specifically Landsat bands 3, 4, 5, and 7. We recomposite a color image by compositing bands 5,4 , and 3 as red, green, and blue bands, which is a similar natural color images.

\section{The midlatitude cooling during warming hiatus}

The warming hiatus has been questioned with regard to data artifacts as well as trend calculation method. The work by Karl et al. (2015) and Rajaratnam et al. (2015) suggested a nonsignificant hiatus in global averaged surface temperature records was found when correcting the errors from commercial ships and drifting surface buoys. However, the difference of land surface temperature between corrected and uncorrected is small (Karl et al. 2015; Jones 2016), which indicates the land observations are reliable. For both the Northern Hemisphere $(\mathrm{NH})$ and Siberia the average SAT anomaly shows a recent warming period followed by a warming slowdown relative to the 1961-90 climatology from the four different datasets (CRU, GISS, GHCN, and corrected NCEI) (Fig. 1). During the warming hiatus, the Siberia temperature anomaly shows a significant cooling period, which is consistent in corrected NCEI and other observations.

The warming hiatus of the NH land SAT in the corrected NCEI dataset is robust, although it claims that the global SAT trend during the first 15 years of the twentyfirst century is at least as great as the second half of the twentieth century. As shown in Fig. 1, Siberia has a larger magnitude of decadal oscillation than the $\mathrm{NH}$ and has experienced the most enhanced warming, especially in the winter season during the last three decades of the twentieth century (1970-98, the so-called accelerated warming period) (Chen and Tung 2014; Tung and Zhou 2013). During the accelerated warming period, the amount of warming was consistent both spatially and temporally. However, there has been a hiatus in the warming trend for the globally averaged surface air temperature since 1998 (the so-called hiatus period). In the hiatus period, the spatial and temporal variations in SAT have become inconsistent. As suggested by Cohen et al. (2012b), global temperatures for the warming hiatus period experienced significant warming trends for all seasons except winter, and the cooling trends are only prevalent across large stretches of northern Eurasia, as shown in Fig. 2. Consistent with the previous studies by 


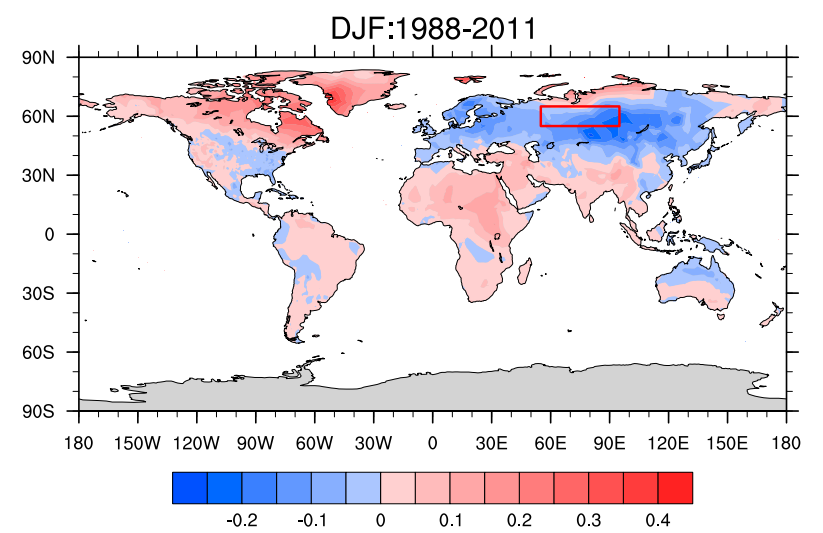

FIG. 2. Global distribution of linear land surface temperature trend $\left({ }^{\circ} \mathrm{C} \mathrm{yr}^{-1}\right)$ in the period of $1988-2011$ for winter season (from December to February). The study region for evergreen forests expansion is indicated by the red box.

Huang et al. (2012), during the accelerated warming period, the cold season contributed much more than the warm season to $\mathrm{NH}$ warming (Fig. 3). The temperature trend of the warm season in Siberia was equal to that of the $\mathrm{NH}$, but the extent of temperature change during the cold season in Siberia was much greater than that in the $\mathrm{NH}$, demonstrating that the temperature trends mainly depend on cold season temperature trends. During the hiatus period, both Siberia and $\mathrm{NH}$ have exhibited warming trends in the warm season. The cooling rate of winter in Siberia is $-0.806^{\circ} \mathrm{C}$ decade $^{-1}$. This is 10 times greater than that of the $\mathrm{NH}$ and is the main reason for the cooling trend in the $\mathrm{NH}$ annual temperature. $\mathrm{Li}$ et al. (2015) confirmed from five different global datasets that the global-mean surface temperature trend in the period 1988-2012 is strongly influenced by a pronounced Eurasian winter cooling trend. The trend in winter temperature across the Northern Hemisphere was investigated from the corrected NCEI dataset, and the same result was obtained with three other datasets (Figs. S1 and S2 in the supplemental material). This winter temperature trend may exert a challenge for the young evergreen conifers to survive during the warming hiatus period.

\section{The expansion of evergreen forest in Siberia}

Innovations in satellite remote sensing instruments are increasing the potential for continental-scale measurements of forest structure (Shugart et al. 2015). To determine whether the transition to evergreen conifer forest has ceased or reversed in response to the temperature cooling as discussed above, the land-cover change during recent decades was evaluated using the MODIS landcover product (Friedl et al. 2010). Comparing the forest

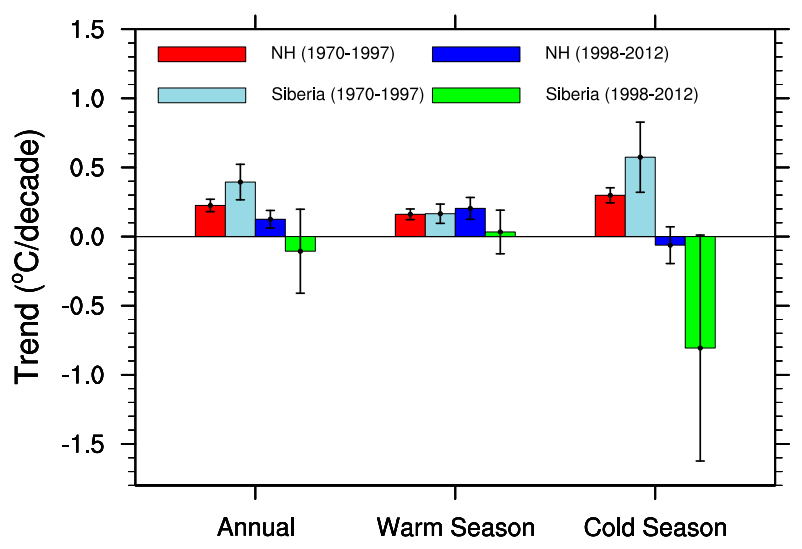

FIG. 3. The average temperature trend for annual, warm season (from May to September), and cold season (from November to March) over Siberia and the NH during the accelerated warming period (1970-97) and hiatus period (1998-2012). Error bars give one std dev.

distribution in 2001 and 2012, the evergreen conifer forests have increased and expanded both from the northwest to the east and from the east to the central area (Figs. 4a-c). In total, the evergreen conifer forest has experienced a $40 \%$ increase, whereas the deciduous conifer forest in Siberia has experienced a $40 \%$ decrease over the last decade (Fig. 4d). These are striking vegetation biogeography changes to occur in one decade. If this is an accurate classification by the satellite data, we hypothesize that temperature remains a dominant factor in producing such changes during the warming hiatus. However, the classification accuracy of deciduous conifer forest $(<50 \%)$ is much lower than that of evergreen forest ( $\sim 70 \%$ ) based on the MCD12Q1 dataset (Fig. S3). In Siberia, Giri et al. (2005) classified a vast area of larch-dominated deciduous conifer forest with low canopy cover as woody savannas or savannas in a global vegetation classification and mapping system. Siberian larch forest with their widely spaced trees may resemble savannas; they are not different enough, and hence a global classification analysis designed for savannas might produce classification errors in the Russian landscape. Here, to clarify the causes of such drastic evergreen conifer forest expansion and to justify our hypothesis, two important questions must be addressed: 1) Were the changes in evergreen and deciduous forest simply an artifact of land-cover classification accuracy? 2) If not, or at least partially not, could natural growth or other factors (e.g., fire) trigger such a change?

\section{a. Confusion between larch and savanna}

The MCD12Q1 collection 5.1 product has an overall accuracy of approximately $75 \%$ and a user's accuracy of $78 \% \pm 5 \%$ and $83 \% \pm 3 \%$ for evergreen conifers and 

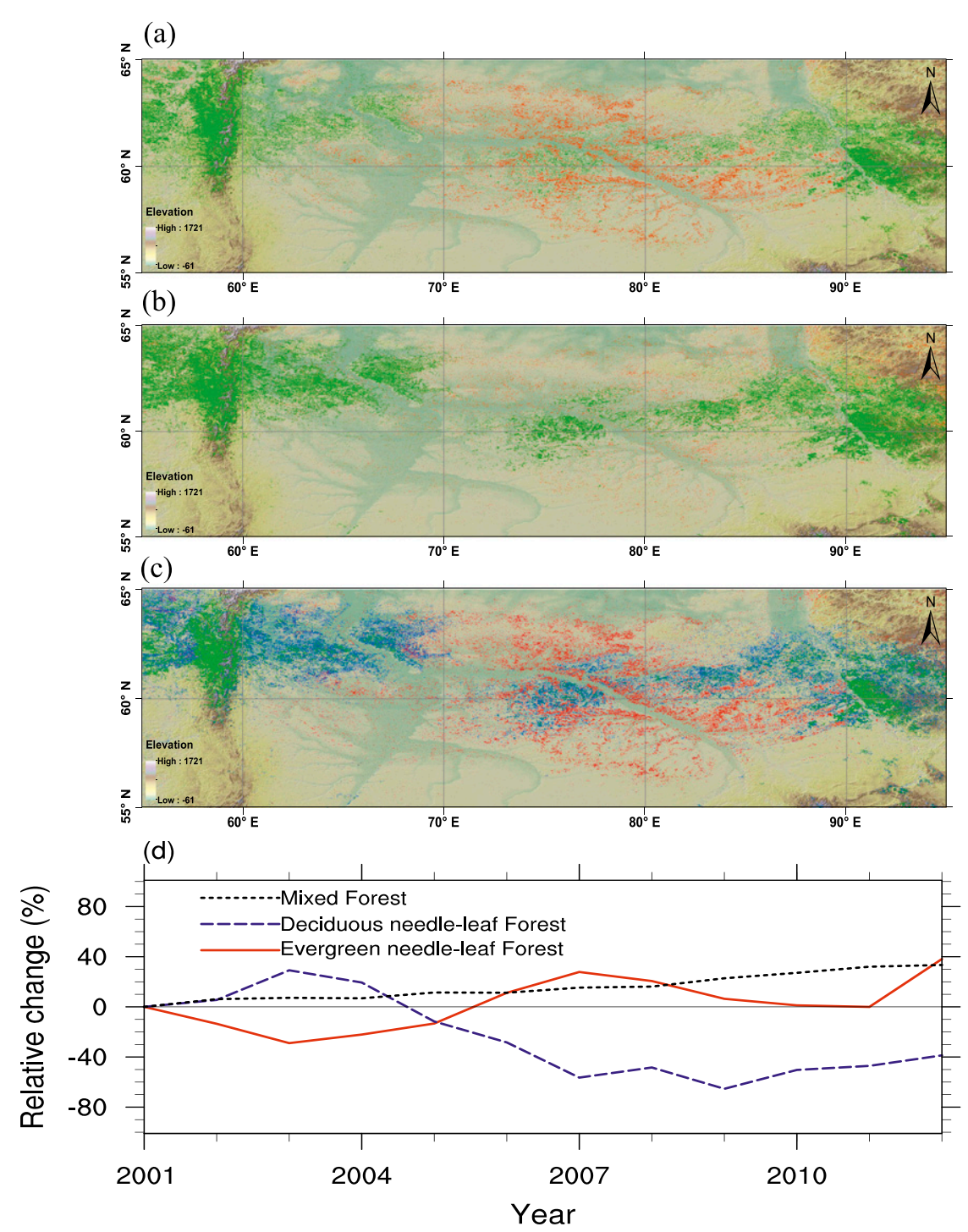

FIG. 4. The distribution of evergreen (green) and deciduous (orange) needleleaf forest in Siberia in (a) 2001 and (b) 2012. (c) The change in evergreen needleleaf forest between 2001 and 2012; green indicates evergreen forest present in both years, blue indicates a change to newly formed evergreen forest in 2012, orange indicates that deciduous forest is present in both years, and red indicates a disappearance of deciduous forest in 2012. (d) The change in area of different forest types from 2001 to 2012.

deciduous conifers, respectively. However, Giri et al. (2005) noted that there is a general agreement at the class level, except for savannas. Within this collection 5.1 version of MCD12Q1, Siberia has approximately 2 million $\mathrm{km}^{2}$ classified as savanna or woody savanna, which, based on vegetation maps and expert knowledge of the region, is actually larch-dominated forest with relatively low canopy cover. To confirm the accuracy of the MCD12Q1 classification, the classification of evergreen and deciduous conifer forests in the study region was investigated (Fig. S3). These results suggested the accuracy for the evergreen conifer forests is generally over $70 \%$, but that of the deciduous conifer forests is lower than $50 \%$. There are extensive areas of savannas/woody savannas contiguous to deciduous conifer forests (Figs. 5a,b). A reanalysis was performed for the Siberian study area using a different classification scheme that labeled woody savannas and savannas as a type of deciduous forest. The changes in the distributions in evergreen and newly defined deciduous conifer forests between 2001 and 2012 demonstrate a pronounced disappearance of deciduous forest and the expansion of evergreen forest (Fig. 5). 
(a) 2001

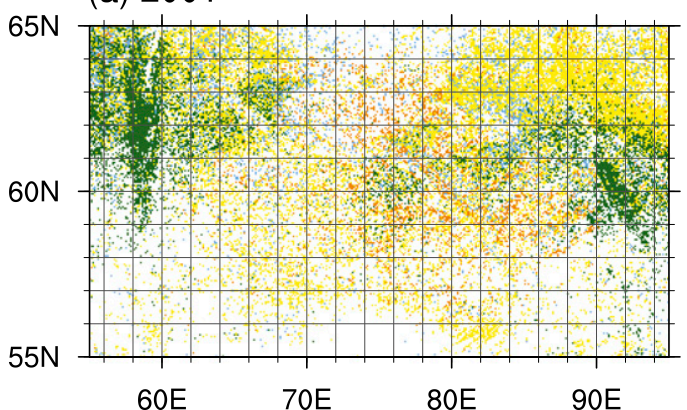

(b) 2012

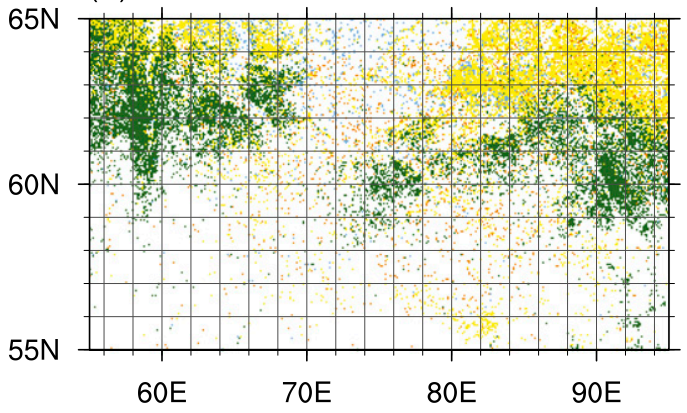

(c)

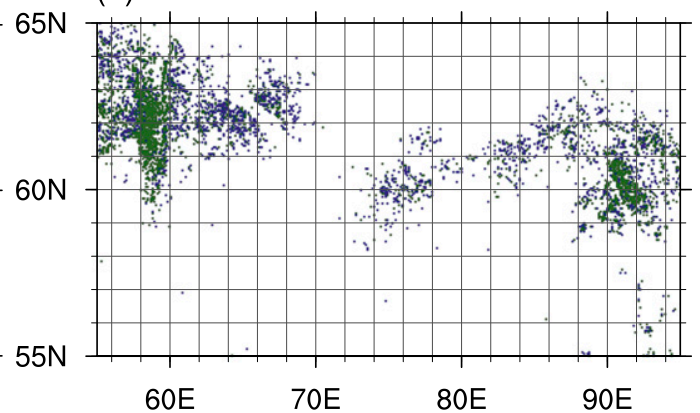

(d)

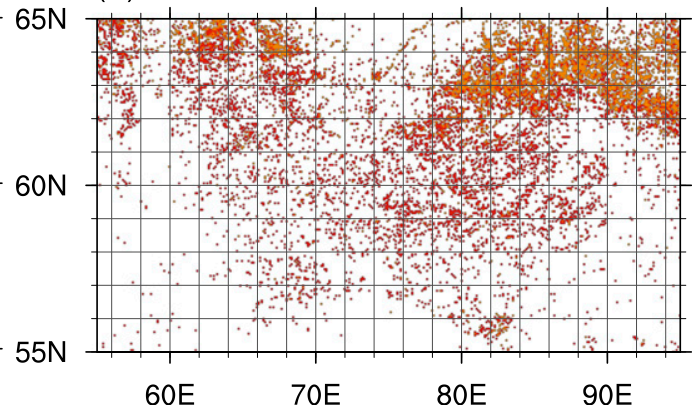

FIG. 5. The distribution of evergreen (green), deciduous (orange) needleleaf forest, woody savanna (yellow), and savanna (blue) in Siberia in (a) 2001 and (b) 2012. The change in (c) evergreen needleleaf forest and (d) deciduous needleleaf forest between 2001 and 2012; green indicates evergreen forest present in both years, blue indicates a change to newly formed evergreen forest in 2012, orange indicates that deciduous forest is present in both years, and red indicates a disappearance of deciduous forest in 2012.

Figure S4 plots the time series of the area of evergreen conifer forest, newly defined deciduous conifer forest, and mixed forest relative to 2001 when considering woody savannas/savannas. Although the area changes of deciduous forests, including woody savannas/savannas, became more gradual than before, the magnitude of the area change was still $40 \%$ (i.e., the same as that without including savannas). Apparently, the changes in evergreen and deciduous forests seen from satellite observation are consistent, regardless of possible confusion over deciduous forest and woody savanna/savanna classification.

\section{b. The mechanism of land-cover change and fire}

Another important question is how much growth is necessary to trigger a change in the land-cover classification. What mechanism is responsible for these changes? To answer this question, we first considered the influence of fire on the land-cover changes. Two fire datasets (MCD45A1 and GFED4s) were used to investigate the fire map during 2001-12. MCD45A1 is a monthly gridded 500-m product based on the Terra and Aqua MODIS-derived daily surface reflectance inputs. The algorithm analyzes the daily surface reflectance dynamics to locate rapid changes and to detect the approximate date of burning. GFED4s provides the monthly burned area based on the burned area boosted by a small fire-burned area. The details are described in Table 1. Figure S5 shows the fire map in every year during 2001-12 based on the MCD45A1 product. The results suggest that fires mainly occurred in the southern part of the research region and that evergreen and deciduous forest areas have few fires, which is consistent with the burn map from GFED4s (Fig. S6). Therefore, fire was not a major agent for the land-cover changes.

To understand the details of the land-cover changes, we further investigated the land-cover map before new evergreen forests formed and after deciduous forest disappeared as shown in Fig. 6. The newly formed evergreen forests mainly occupy areas previously occupied by mixed forest and woody savannas/savannas. There are two possible reasons for this phenomenon. First, the tree cover percentage $(\sim 30 \%)$ is very low, both in the new expansion area of the evergreen forest and in the disappearance area of the deciduous forest. The low threshold reduces the difficulty of changing the dominant tree species. The IGBP classification scheme requires that the trees are greater than $2 \mathrm{~m}$ in height; we hypothesis that the decision trees used in MODIS collection 5 can determine the changes of tree cover. The 
landcover type in new evergreen area
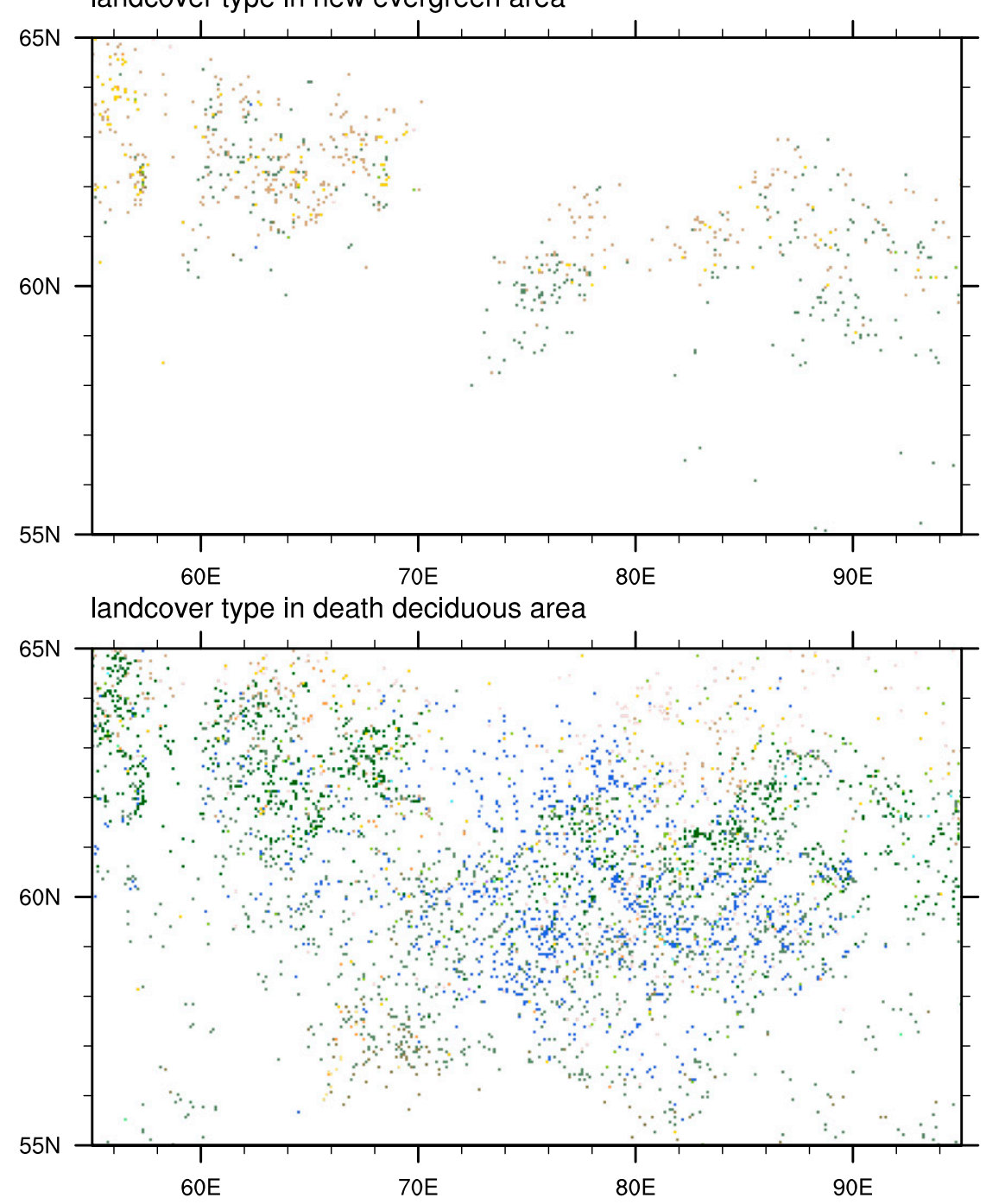

\begin{tabular}{|l|l|l|l|l|l|l|l|l|l|l|l|l|l|l|l|l|}
\hline 0 & 1 & 2 & 3 & 4 & 5 & 6 & 7 & 8 & 9 & 10 & 11 & 12 & 13 & 14 & 15 & 16 \\
\hline
\end{tabular}

FIG. 6. The land-cover type in (top) newly formed evergreen area in 2001 and (bottom) disappearing deciduous area in 2012. The legend is from the IGBP classification scheme: $0=$ water, 1 = evergreen needleleaf forest, $2=$ evergreen broadleaf forest, $3=$ deciduous needleleaf forest, $4=$ deciduous broadleaf forest, $5=$ mixed forest, $6=$ closed shrublands, $7=$ open shrublands, $8=$ woody savannas, $9=$ savannas, $10=$ grasslands, $11=$ permanent wetlands, $12=$ croplands, $13=$ urban and buildup, $14=$ cropland/natural vegetation mosaic, $15=$ snow and ice, and $16=$ barren or sparse vegetation.

evergreen regeneration may have already existed in a mixed forest or savanna but was not detected by the MODIS sensor because the trees were lower than the height threshold. Evergreen trees that are regenerating can reach $2 \mathrm{~m}$ over a relatively short interval under favorable conditions and become more observable relative to the deciduous conifers. The second possibility is that mixed forest transition to evergreen forest is part of a general phenomenon of the deciduous forest shrinkage because of its lack of tolerance to shade. In a mixed forest, deciduous regeneration is negligible, whereas original deciduous trees survive because of their longevity. Alternatively, the reclassified deciduous forests, which include woody savannas/savannas, disappeared and transitioned to evergreen forest, mixed forest, and permanent wetland. Note that the "deciduous forests" include woody savannas/savannas. It can be inferred that the woody savannas/savannas are 
(a)

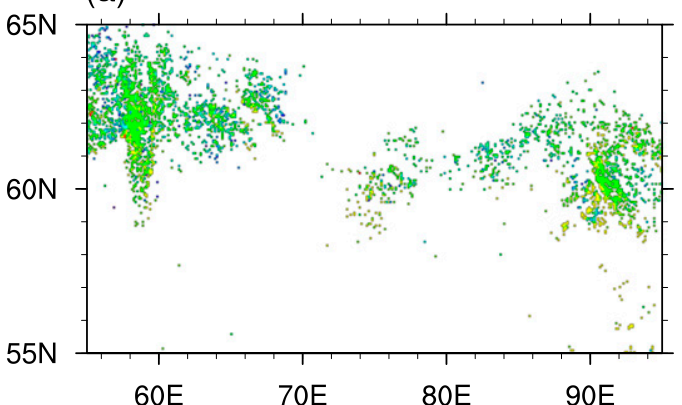

(b)

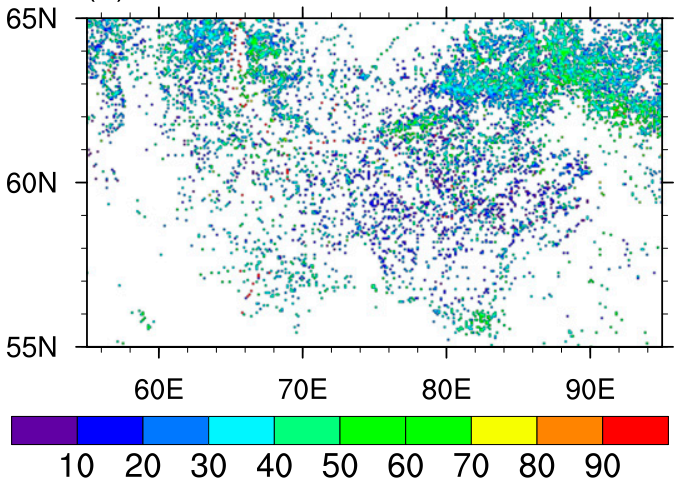

(c)

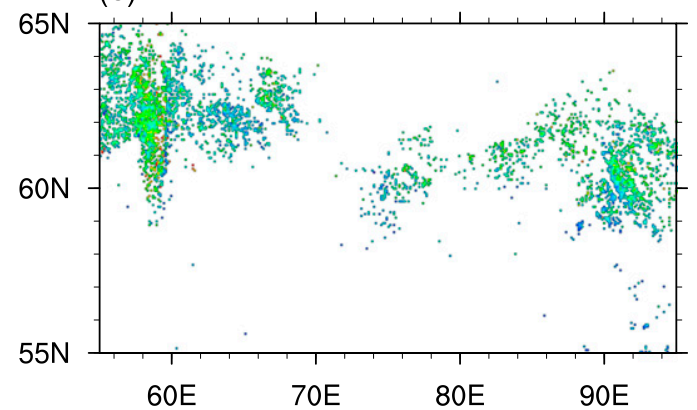

(d)

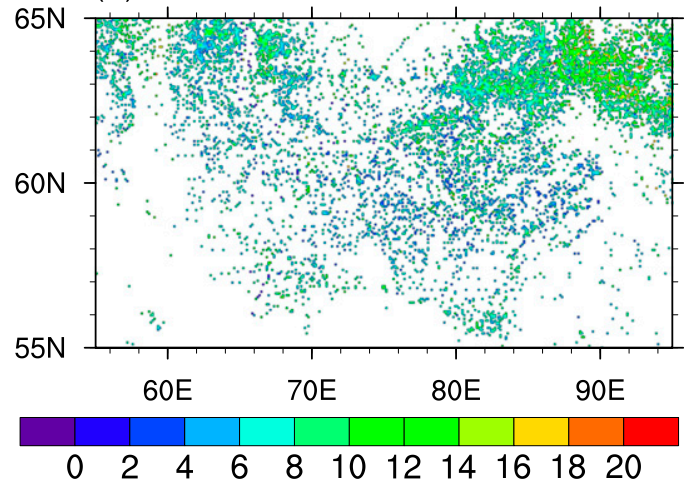

FIG. 7. The average percentage tree cover in (a) evergreen and (b) deciduous forest from 2001 to 2012 . The std dev of percentage tree cover in (c) evergreen and (d) deciduous forest from 2001 to 2012.

not totally sparse larch-dominated deciduous forests; in fact, some savannas areas are dominated by sparse evergreen forests. The tree cover percentage increased and exceeded the threshold to be classified as evergreen forest. This result demonstrates that the transition from deciduous forest to evergreen forest likely occurs through mixed forest or woody savannas as a buffer. It is possible for evergreen species to become dominant through growth in a mixed-species forest because the difference in cover percentage between evergreen and deciduous trees may be not very large. Moreover, because the threshold of classification as woody savannas/ savannas and forest is fixed, an area with a tree cover slightly lower than the threshold would be classified as woody savannas, when, in reality, it nearly meets the definition of forest.

\section{c. Validation of the land-cover change using the vegetation continuous field}

To confirm the above conclusion, we analyzed the Terra MODIS vegetation continuous field (VCF) product. The VCF is a subpixel-level representation of the surface vegetation cover estimates globally and provides three surface cover components: percent tree cover, percent nontree cover, and percent base. Other information is described in Table 1. The MODIS reprojection tool was used to change raster images from 250- to 500-m resolution to enable comparison with the other MODIS datasets. To further verify that the landcover change is due to growth rather than fire, the change in percent tree cover in every grid was investigated to detect an abrupt change induced by fire or logging. The averaged percent tree cover in evergreen forests showed an overall fraction of $60 \%$ (Fig. 7a) and a fraction of around $20 \%-40 \%$ for deciduous forests

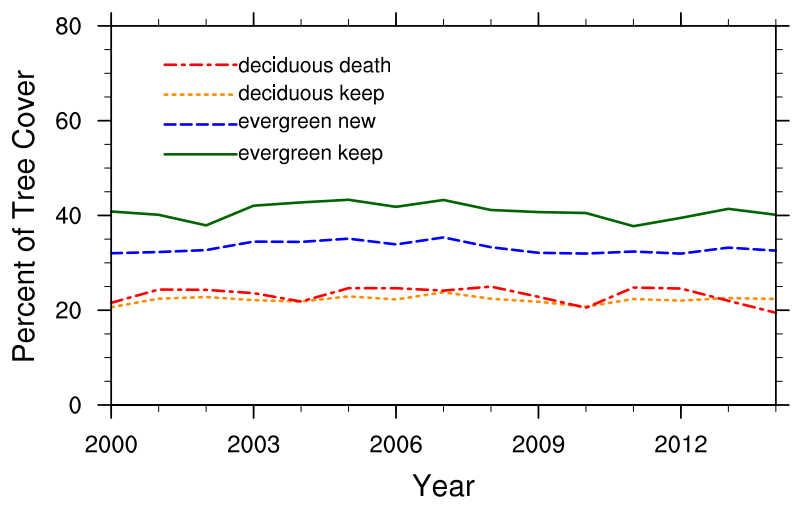

FIG. 8. The time series of averaged tree cover percent in evergreen keep (green), new (blue), deciduous keep (orange), and death (red) area. 
(a) 2002

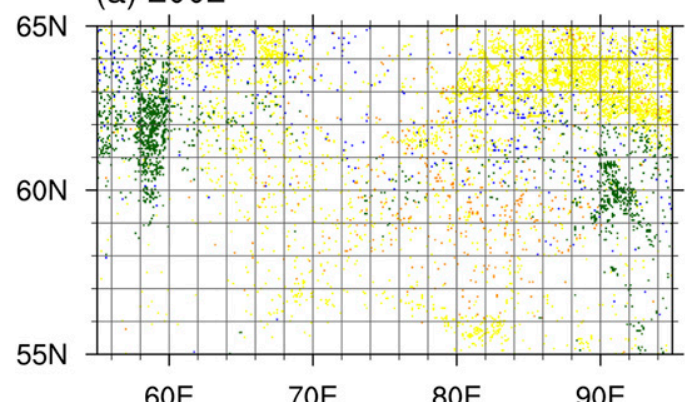

(b) 2011

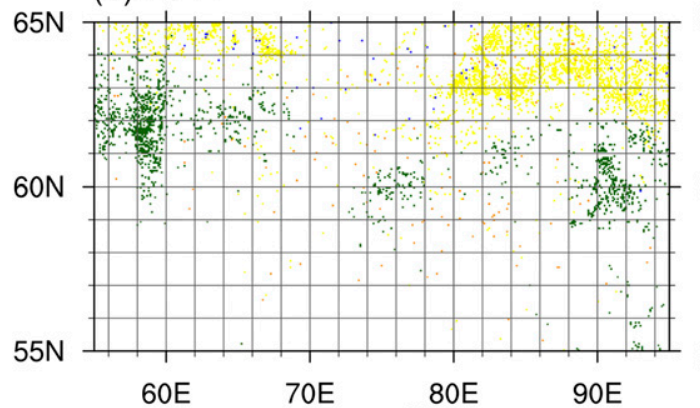

(c)

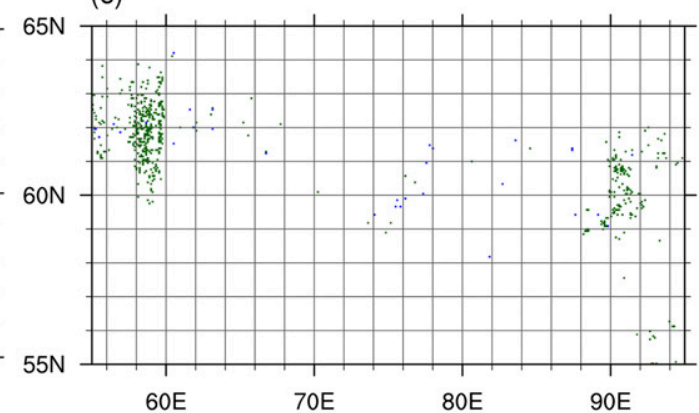

(d)

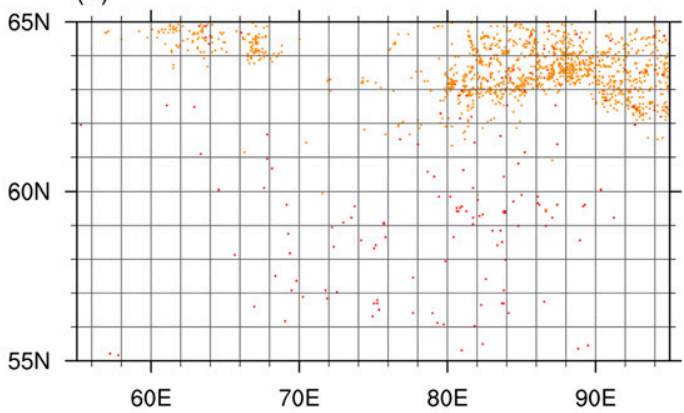

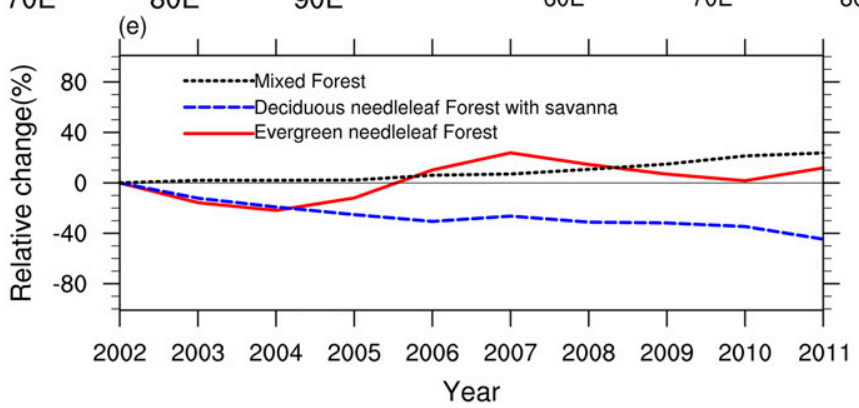

FIG. 9. The distribution of evergreen (green), deciduous (orange) needleleaf forest, woody savanna (yellow), and savanna (blue) in Siberia in (a) 2002 and (b) 2011 after a 3-yr running average. The change in (c) evergreen needleleaf forest and (d) deciduous needleleaf forest between 2002 and 2011 (legend as in Fig. 5). (e) The change in area of different forest types from 2002 to 2011 through the 3-yr running average.

(Fig. 7b), with an associated standard deviation of between $4 \%$ and $14 \%$ for evergreen and deciduous forests, respectively (Figs. 7c,d). If fire occurred in a forest, then the percent tree cover would exhibit an abrupt change in the burned area, which is unable to recover to the original level in a short period. However, the standard deviation maps show a consistent pattern with the average percent map, which means the changes in percent tree cover were due to natural succession but not fire. In addition to the spatial pattern check, a temporal check was performed to detect any abrupt change in the percent tree cover. Figure 8 shows the time series of the percent tree cover in four types of forests. The areas both classified as evergreen forest in 2001 and 2012 are denoted as "evergreen keep," the areas classified as evergreen forest in 2012 and others in 2001 are denoted as "evergreen new." Similarly, deciduous forest can be divided into "deciduous keep" and "deciduous death." The results suggest that the percent tree cover did not exhibit an abrupt change during 2001-12.

\section{$d$. The influence of classification algorithm}

Although the collection 5 MODIS global land-cover type product has been substantially improved, experience from previous MODIS collections show that the deciduous needleleaf forest is problematic and difficult to map (Friedl et al. 2010). To correct this, trial and error are extensively used to identify a probability threshold, which, if not exceeded by the classifier, causes deciduous needleleaf pixels to be relabeled as the next most likely class (Friedl et al. 2010). The unstable algorithm could overestimate the amount of interannual change in landcover classifications in heterogeneous areas and ecotones and tend to toggle year to year between similar 
classes. Therefore, additional efforts are needed to determine what is happening on the ground and how much the idiosyncrasies of the classification algorithm may contribute to the apparent shift from deciduous needleleaf forest to evergreen forest.

\section{1) StABilization of RESUlt ACROSS YeARS}

To reduce the year-to-year variability in land-cover classifications, we applied a 3-yr running averaged method to determine the stability of land-cover changes due to climate changes. The changes of land-cover classifications in one grid are considered to be stable if the classifications in the previous and following year are consistent with that in the current year. Using this method, we eliminated many spurious pixels arising from the unstabilized classification algorithm and perpetuated high-quality labels, accounting for the possibility of land-cover change. Figures $9 a$ and $9 b$ show the distributions of evergreen forest and deciduous forest with savannas in 2002 and 2011 after applying the stabilization. The results suggested that the unstable classification mainly distributed in the dispersed evergreen forest or deciduous forest, whereas most of the dense areas are stable. The expanded area of stable evergreen forest from 2002 to 2011 significantly decreased compared with the expansion without applying the stabilization. However, the newly formed evergreen forest can also be found around the dense evergreen forest and at the center of the study area (Fig. 9c). The sparse deciduous forest over the southward of $60^{\circ} \mathrm{N}$ largely disappeared (Fig. 9d), which was consistent with the change without stabilization. Figure 9e shows the time series of the stable classifications in different forest types from 2002 to 2011. Compared to Fig. $4 \mathrm{~d}$, when considering the accuracy of classification (evergreen conifer forest $\sim 70 \%$ and deciduous conifer forest $\sim 50 \%$ ), the area of expansion of evergreen forest reduced to about $10 \% \pm 3 \%$ and the area of disappearance of deciduous forest was $40 \% \pm 20 \%$. It should be noted that this level of changes is still well above the amount of actual land-cover change. The results suggested that the classification algorithm may have a large influence on the extent of land-cover change but not enough to change the pattern induced by climate change. The trend of forest changes has an important implication for the response of forest to climate changes.

\section{2) The ACCURACY ASSESSMENT}

To exclude the idiosyncrasies of the algorithm used in the MODIS collection, a more independent common validation such as an accuracy assessment should be done for the study area. For this purpose, different remote sensing land-cover products, developed from multispectral and multitemporal imagery, are available to
TABLE 2. Harmonized legend used and correspondence with original product classes.

\begin{tabular}{lrr}
\hline \multicolumn{1}{c}{ Classes } & Globcover 2009 & MODIS \\
\hline Evergreen needleleaf forest & 70 & 1 \\
Evergreen broadleaf forest & - & 2 \\
Deciduous needleleaf forest & 90 & $3,8,9$ \\
Deciduous broadleaf forest & 50,60 & 4 \\
Mixed forest & 40,100 & 5 \\
Mixed forest-shrub & 110,12 & - \\
Shrub & 130 & 6 \\
Sparse vegetation & 150 & 7,16 \\
Herbaceous regularly flooded & 180 & 10 \\
Herbaceous & 30,140 & - \\
Urban & 190 & 13 \\
Bare soil & 200 & - \\
Snow/ice & 220 & 15 \\
Water & 210 & 0 \\
Croplands & $11,14,20$ & 12,14 \\
\hline
\end{tabular}

separate the various ecosystems presenting different spectral properties and seasonal variations (Ottlé et al. 2013). The most popular and most recent products are the GlobCover 2009 derived from the Medium Resolution Imaging Spectrometer (MERIS) radiometer and the MODIS land-cover dataset based on Terra and Aqua MODIS instruments (Ottlé et al. 2013). Here, we compared the agreement between two independent land-cover datasets to exclude the influence of algorithm.

GlobCover 2009, based on Envisat/MERIS data acquired in year 2009, is available in plate carrée projection [Word Geodetic System 1984 (WGS84)] with a 300-m spatial resolution and uses a different classification system from MODIS. Therefore, a harmonization procedure is needed. As discussed in previous studies focusing on land-cover map cross comparison (Pflugmacher et al. 2011; Ottlé et al. 2013), a common legend needs to be based on PFT features and to discriminate trees, shrubs, water, and barren as well as leaf type and senescence. This leads us to merge the classification legend use in the MCD12Q1 and GlobCover 2009 under 15 classes as listed in Table 2.

An assessment of the overall accuracy of the two landcover datasets is presented using error matrices and Cohen's kappa (Jensen 2015). Table 3 quantifies the disagreement in an error matrix for 15 categories. The GlobCover 2009 classifications are confirmed by MODIS relatively well for deciduous needleleaf forest $(65 \%)$, cropland $(64 \%)$, and sparse vegetation (43\%), but the agreement declines precipitously for the remaining categories. In turn, the MODIS classification is confirmed by GlobCover 2009 relatively well for cropland (85\%), mixed forest $(72 \%)$, and water $(56 \%)$. The overall accuracy between MODIS and GlobCover 2009 is only 


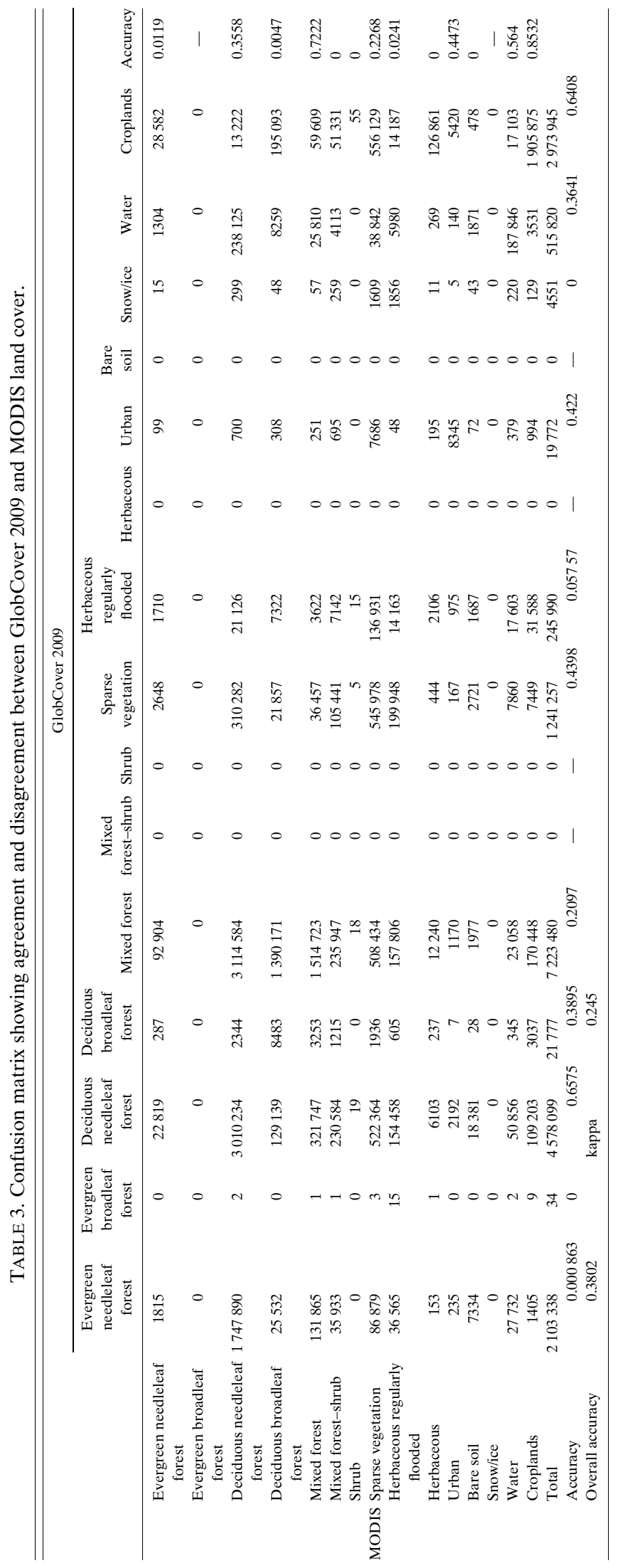


$38 \%$ for the study area, with a kappa coefficient of 0.245 , which is consistent with previous results (Frey and Smith 2007). The evergreen needleleaf forest in MODIS was mainly confounded by deciduous needleleaf and mixed forest, indicating that the evergreen forest may exist in the deciduous forest pixel or vice versa. Another factor influencing the classification results is the definition of land cover. For example, GlobCover 2009 defines the land cover with $>15 \%$ tree cover (woody plants larger than $5 \mathrm{~m}$ ) as forest, whereas IGBP (used in MODIS) defines the land cover with $>60 \%$ tree cover (woody plants larger than $2 \mathrm{~m}$ ) as forest. Although there is a low agreement between the two datasets, GlobCover 2009 showed a significant increase of evergreen needleleaf forest by about $35 \%$ relative to 2005 (not shown), which is certainly overestimated.

\section{3) COMPARISON WITH HIGH-RESOLUTION IMAGES}

To address how the apparent transition is occurring and its ecological significance, we undertook a comparison between MODIS land-cover changes and highresolution Landsat composite images in six stratified random reference sites. Figure 10 shows the locations of the six reference sites (Table 4), including three sites in newly formed evergreen forest (sites 1-3) and three sites in the area where deciduous forest disappeared (sites 4-6). Hansen et al. (2013) mapped global tree cover extent, loss, and gain from 2000 to 2012 at a spatial resolution of $30 \mathrm{~m}$ based on Landsat data, which provided us an opportunity to investigate the changes of evergreen forest by high-resolution images.

Although the MODIS land-cover dataset has a large uncertainty in the deciduous forest, it is clear that the evergreen forest mainly distributes around the dense area, whereas the deciduous forest prefers a dispersed distribution. Therefore, it is feasible to investigate the change of evergreen forest and deciduous forest by investigating the forest gain and loss. Figure 11 shows the Landsat composite images and the distribution of forest gain and loss at the reference sites. Based on the MODIS land-cover dataset, sites 1-3 are located in the newly formed evergreen forest, with an expectation of more forest gain and less forest loss than the others, whereas sites 4-6 are located in the disappearance area of deciduous forest, with an expectation of less forest gain and more forest loss than others. With a comparison between the high-resolution images in 2000 and 2014 at different sites, it is clear that there was a significant increase of evergreen forest in site 2 and a significant decrease of deciduous forest in site 5 . However, in site 1, there are no significant changes in the extent of forest. In the north of site 3 , there is a large continuous area of forest loss, which may be caused by fire. In contrast to site 5 , sites 4 and 6 did not have many changes in the extent of deciduous forest, but the deciduous forest area shows a relative weaker green (Fig. 11), which may imply the decrease of deciduous forest fraction in the grid due to climate changes.

To quantify the forest gain and loss, we calculated the area of the forest gain and loss in the area where evergreen forests expand at sites 1-3 or deciduous forests disappear at sites 4-6 (Fig. 12). Because fire might occur in site 3 and induce a large amount of forest loss, the forest loss in site 3 was far more than the forest gain. The forest gain in site 2 was consistent with expected result and showed more forest gain than forest loss; however, the forest changes in site 1 were unexpected. In the deciduous forest, forest loss was expected to be more than forest gain, which was found in sites 4 and 5 and had an opposite condition in site 6 . It is noteworthy that the amount of area of forest gain and loss was much less than that of the no gain or no loss grids. The result suggested that the newly formed evergreen forest or the disappeared deciduous forest in the MODIS land-cover dataset was not mainly induced by the stand-replaced disturbance represented by forest gain or loss. The forest changes not induced by stand-replaced disturbance were consistent with that induced by stand-replaced disturbance. The forest that did not go through stand-replaced changes in sites $1,3,4$, and 5 has shown a weaker green, which may imply the fraction of forest decrease. In summary, the forest changes in the three sites supported the expansion of evergreen forest and the disappearance of deciduous forest in all five valid sites (site 3 was invalid owing to fire disturbance). During the growing season, we cannot distinguish the evergreen forest from deciduous forest in the high-resolution images by eye. Therefore, more high-quality images observed in winter may help determine the extent of changes in evergreen forest and deciduous forest.

\section{The simulated response of Siberian forest to warming hiatus}

UVAFME is an updated version of the Far East (FAREAST) model (Yan and Shugart 2005), which is an individual-based gap model (IBM) of forest dynamics. Differing from dynamic global vegetation models (DGVMs) that use plant functional types (PFTs), IBMs are a combination of equilibrium models and biogeochemical ecosystem process models (Prentice et al. 2007). PFTs represent broad vegetation classes in the simulation, thus losing the ability to predict individual species response to changes in environmental conditions. IBMs have the ability to describe biogeochemical processes from the individual tree perspective. The use of individuals rather than PFTs has been demonstrated to be more capable of predicting the forest composition 


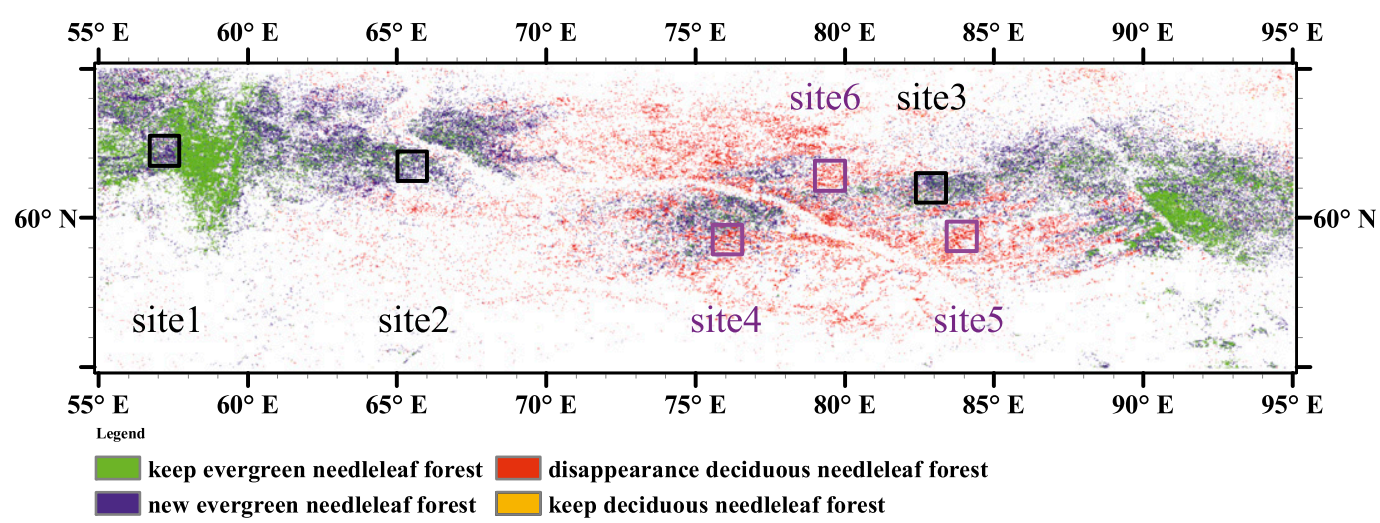

FIG. 10. The locations of six reference sites. The background is the change in evergreen and deciduous needleleaf forest between 2001 and 2012; green indicates evergreen forest present in both years, blue indicates a change to newly formed evergreen forest in 2012, orange indicates that deciduous forest is present in both years, and red indicates a disappearance of deciduous forest in 2012.

response to climate change (Smith et al. 2001). UVAFME simulates individual trees, specifically their growth, mortality, and regeneration, in a relatively small area and accounts for competition among individuals of multiple tree species for light, water, and nitrogen resources (Yan and Shugart 2005; Shuman et al. 2011). The model has been verified and validated for a variety of forests across Eurasia and China and is currently being adapted for North America. Validation in Russia indicated that UVAFME successfully captures the natural biomass dynamics of mixed-species forest across the varied climate change across Russia (Yan and Shugart 2005; Shuman et al. 2011, 2014, 2015).

To elucidate the successional patterns and rates of change potentially resulting from interactions among a warming, a warming hiatus, and an increase of evergreen conifer forest, the forest dynamics simulations are conducted with two different temperature change scenarios at 100 sites across central Siberia (Fig. S7). For the base scenario, no changes are made to values from the distributions of monthly temperature and precipitation data derived from historical records. Daily temperature and precipitation conditions at each site in UVAFME are derived from statistical distributions of mean monthly temperature and precipitation from 60 years of weather station data for the period from 1941 to 2001 (NCDC 2005a,b). Scenario 1 uses a linear increase in temperature to $4^{\circ} \mathrm{C}$ from year 0 to year 200 of the simulation, followed by an additional 300 years of simulation, during which the climate stabilizes around the condition attained in year 200 (Figs. 13b and 9b). Compared to the base run, scenario 1 demonstrates that the UVAFME model effectively simulates the succession dynamics and response of the forest to warmer climate. To investigate the effect of decadal oscillations on the altered forest, the temperature in scenario 2 has an added decadal oscillation on the equilibrium temperature attained in year 200 (Figs. 13b and $9 \mathrm{~b}$ ). The decadal oscillation was extracted from the observational temperature using the ensemble empirical mode decomposition (EEMD) method (Figs. S8-S10). Figures 9 and 13 show the cumulative biomass change over 500 years under two scenarios. In the control run with historic climate, the forest succession consists of an initial pioneering stage dominated by the deciduous conifer (Larix), which, when averaged over 200 simulations at each of the 100 sites over the local area, transitions to evergreen conifer forests dominated by Pinus (Figs. 9a and 13a). The succession from deciduous conifers (Larix spp.) to evergreen conifers (Pinus spp.) is accelerated with increasing temperature (Figs. 9c and 13c).

Comparing the simulated forest equilibria, the warmer climate changes the forest composition and nearly eliminates deciduous conifers. However, when a decadal variability in the temperature is introduced (Figs. 9b and 13b), the evergreen conifer species biomass fluctuates but the equilibrium total biomass remains unchanged (Figs. 9c,d and 13c,d). During the positive phase of a decadal oscillation with enhanced temperature, the deciduous conifer biomass decreases, while the evergreen conifer biomass increases (Figs. 9d and

TABLE 4. The locations of six sites.

\begin{tabular}{cll}
\hline \hline Site number & \multicolumn{1}{c}{ Lat range } & \multicolumn{1}{c}{ Lon range } \\
\hline 1 & $61.75^{\circ}-62.75^{\circ} \mathrm{N}$ & $56.70^{\circ}-57.70^{\circ} \mathrm{E}$ \\
2 & $61.24^{\circ}-62.24^{\circ} \mathrm{N}$ & $65.0^{\circ}-66.0^{\circ} \mathrm{E}$ \\
3 & $60.51^{\circ}-61.51^{\circ} \mathrm{N}$ & $82.38^{\circ}-83.38^{\circ} \mathrm{E}$ \\
4 & $58.78^{\circ}-59.78^{\circ} \mathrm{N}$ & $75.57^{\circ}-76.57^{\circ} \mathrm{E}$ \\
5 & $58.88^{\circ}-59.88^{\circ} \mathrm{N}$ & $83.43^{\circ}-84.43^{\circ} \mathrm{E}$ \\
6 & $60.92^{\circ}-61.92^{\circ} \mathrm{N}$ & $79.0^{\circ}-80.0^{\circ} \mathrm{E}$ \\
\hline
\end{tabular}




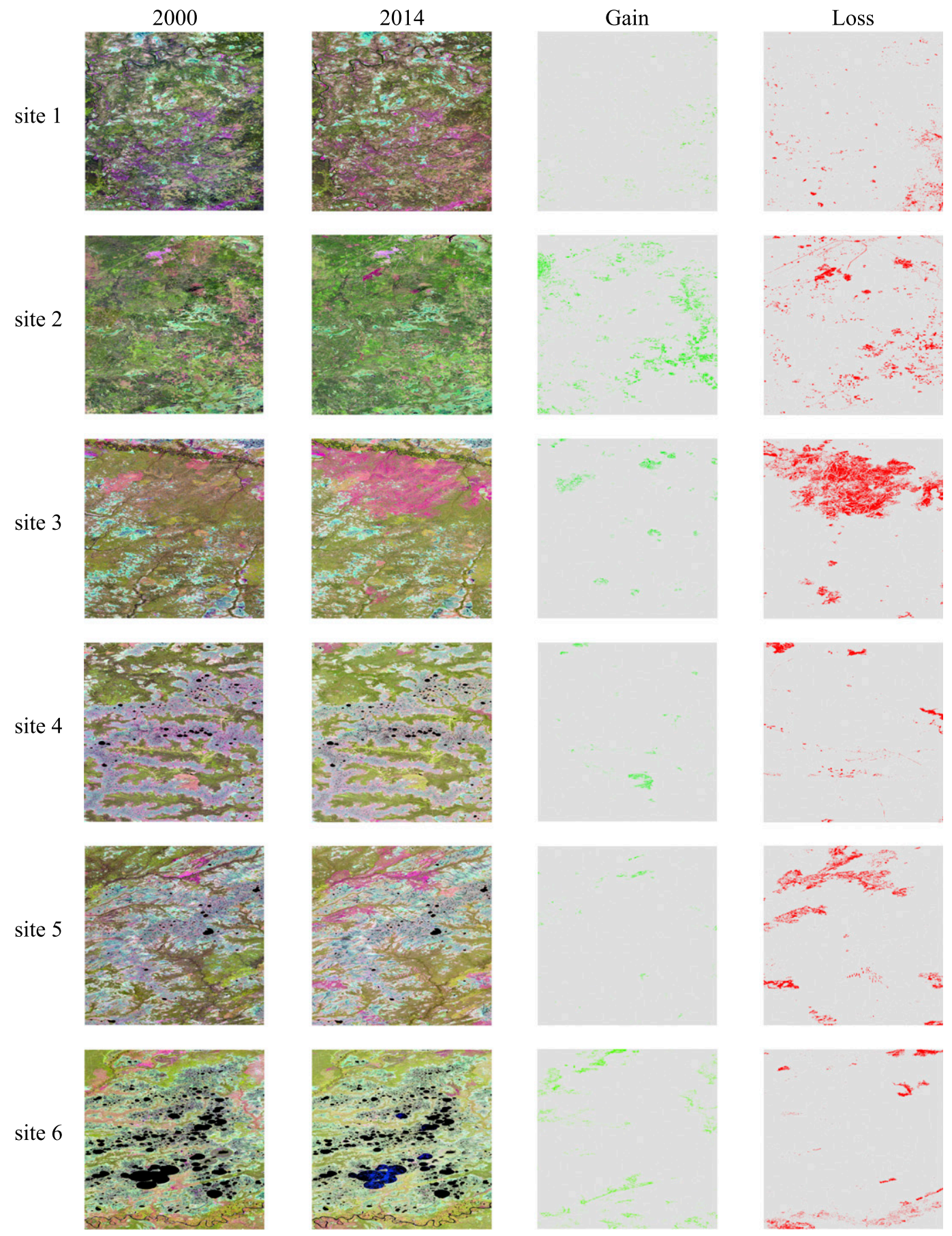

FIG. 11. The distribution of vegetation from cloud-free high-resolution Landsat composite images over six sites in 2000 and 2014 and the corresponding distribution of forest gain and forest loss during 2000-14.

13d). During the negative phase of decadal oscillation, the biomass of the evergreen conifers does not change with the decadal oscillation included in scenario 2 . The deciduous conifer biomass remains constant for scenario 2, oscillating around equilibrium (Figs. 9d and $13 \mathrm{~d})$. The natural decadal oscillation of the temperature does not stop the increase in evergreen conifers. This sensitivity experiment implies that the current conversion to evergreen conifer forests is a consequence of long-term warming and that occasional cooler spells, induced by internal climate oscillations, will not stop this conversion. 


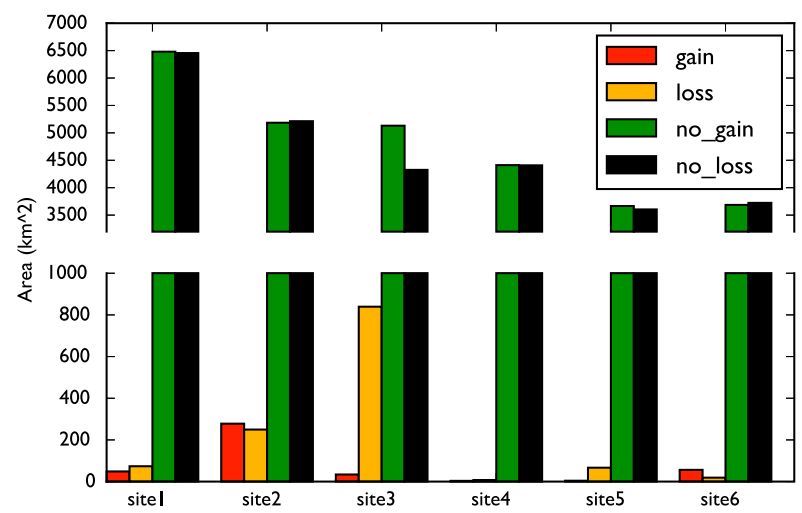

FIG. 12. The histogram of the area of four kinds of forest changes (gain: red; loss: orange; no gain: green; no loss: black) in six sites during 2000-14.

\section{Discussion and conclusions}

In this study, the warming hiatus of the SAT trend across the Northern Hemisphere and Siberia was investigated from four different datasets including the corrected NCEI dataset. The result suggests that the warming hiatus over 1998-2012 is a robust phenomenon, although the warming trend may be underestimated by ocean data biases as suggested by Karl et al. (2015). The cooling trend during winter season in the Eurasian continent contributes most to the warming hiatus of land SAT trend over recent decades ( $\mathrm{Li}$ et al. 2015). Although Kosaka and Xie (2013) reproduced the globalmean surface temperature trend by using observed sea surface temperature anomalies over the tropical eastern Pacific to force the coupled climate model, the winter cooling trend in Eurasia was not found in the simulation result. As suggested by Cohen et al. (2012a), the observed Eurasian winter cooling may arise essentially from increasing Eurasian snow cover during the warming hiatus period related to atmosphere internal variability in midand high latitudes such as NAO or PDO.

The response of Siberian forest composition to warming hiatus or cooling winter was further investigated by satellite observations and model simulations. The remote sensing results indicate that the expansion of evergreen conifer forests did continue during the warming hiatus. During the last decade, evergreen conifer forest increased $10 \%$ and deciduous conifer forest decreased $40 \%$ in the study region. These magnitudes of
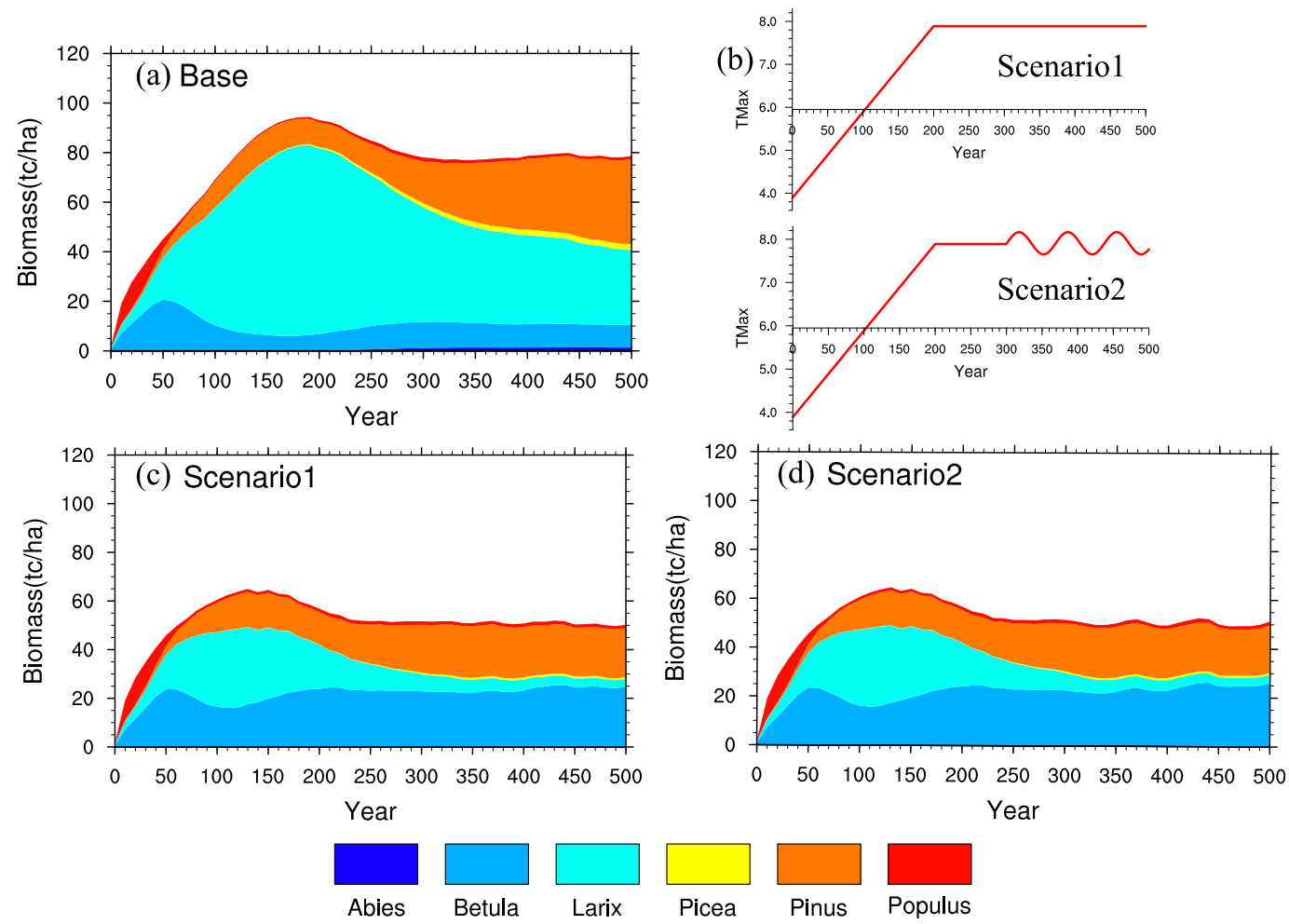

FIG. 13. (a) Simulated cumulative biomass $\left(\mathrm{tC} \mathrm{ha}^{-1}\right.$; where $\left.1 \mathrm{ha}=10000 \mathrm{~m}^{2}\right)$ of species over 500 years for Siberia under the base scenario. (b) The time series of the max temperature under four scenarios. (c),(d) As in (a), but for stable warmer temperature and for the oscillating increased temperature scenario. Deciduous conifers include Larix, and evergreen conifers include Abies, Picea, and Pinus. 
change are consistent with that of treating woody savannas/savannas as deciduous forest in land-cover classifications. Moreover, fire was not found to be responsible for the land-cover changes. The transition of deciduous conifer forest to evergreen conifer forest is usually through mixed forest or savannas. Although we have demonstrated the expansion of evergreen conifer forest in central Siberia, the magnitude of land-cover/ ecosystem changes has a large uncertainty due to the classification algorithm. Because of the large differences between evergreen and deciduous conifer forest, the albedo product or the high-quality images observed from visible bands may help distinguish the extent of evergreen and deciduous conifer forest and reduce the uncertainty of magnitude of evergreen forest expansion. The simulation sensitivity experiments demonstrate that warming has a significant effect on forest composition changes, but cooling spells induced by internal climate variability cannot stop the expansion of evergreen conifer forests. This may be explained by the hysteretic theory proposed by Shugart et al. (1980). The conversion of the evergreen conifer forest, once established, requires the temperature to surpass and persist below the critical value for change to occur. Although the temperature in Siberia has been cooling during the current hiatus, it remains higher than that in the previous hiatus (1940-60) because temperature has been monotonically increasing. The forest ecosystem dynamics and the resultant hysteretic responses suggest that the current hiatus is unlikely to reverse the formation of evergreen conifer forests in zones resulting from warming in the former deciduous conifer zone of the northern boreal forest.

The global surface temperature in the twenty-first century is projected to continue to warm by $4^{\circ}-10^{\circ} \mathrm{C}$. Once the accelerated warming resumes, the evergreen conifer forest conversion may become much severer and even more irreversible. However, it should be noted that the composition of future forest could also be adversely affected by change in permafrost and fire disturbance regime. The fire frequency is predicted to increase with warming, which supports the scenario of larch regaining dominance owing to its resistance to frequent fire (Kharuk et al. 2005a). Removal of overlying vegetation under increasing fire disturbance can accelerate permafrost thawing but apparently not to the soil depth required to support evergreen conifer forest in eastern Siberia (Tchebakova et al. 2009). Although fire and permafrost both limit the eastward and northward expansion of evergreen forests, the potential transition of the forest composition is substantial in western Siberia, where permafrost is seasonal or sporadic. The influences of fire, drought, and permafrost on the future projection of forest composition need further research.
Acknowledgments. We thank Jacquelyn Kremper Shuman for providing model input data and useful discussions and editing. Jianping Huang, Xiaodan Guan, and Yongli $\mathrm{He}$ are jointly supported by the National Science Foundation of China (41521004, 41575006, and 91637312), the China 111 project (No. B13045), and the Foundation of Key Laboratory for Semi-Arid Climate Change of the Ministry of Education in Lanzhou University from the Fundamental Research Funds for the Central Universities (lzujbky-2017-bt04). Herman Henry Shugart is supported by the Center for Global Inquiry and Innovation at the University of Virginia. Yongli $\mathrm{He}$ is also supported by the China Scholarship Council. The authors acknowledge NASA's Earth-Sun System Division (ESSD) for providing the MODIS Adaptive Processing System (MODAPS) datasets. The landcover data product is courtesy of the online Data Pool at the NASA Land Processes Distributed Active Archive Center (LP DAAC), USGS/Earth Resources Observation and Science (EROS) Center, Sioux Falls, South Dakota (https://lpdaac.usgs.go/data_access). The authors also acknowledge NOAA's National Centers for Environmental Information for providing the GHCN dataset and corrected NCEI dataset used in Karl et al. (2015).

\section{REFERENCES}

Bonan, G. B., 2008: Forests and climate change: Forcings, feedbacks, and the climate benefits of forests. Science, $\mathbf{3 2 0}$, 1444-1449, doi:10.1126/science.1155121.

Chen, X., and K.-K. Tung, 2014: Varying planetary heat sink led to global-warming slowdown and acceleration. Science, 345, 897903, doi:10.1126/science.1254937.

Cohen, J. L., J. C. Furtado, M. A. Barlow, V. A. Alexeev, and J. E. Cherry, 2012a: Arctic warming, increasing snow cover and widespread boreal winter cooling. Environ. Res. Lett., 7, 14007, doi:10.1088/1748-9326/7/1/014007.

$-, \ldots,-, \ldots$, and,$- 2012 \mathrm{~b}$ : Asymmetric seasonal temperature trends. Geophys. Res. Lett., 39, L04705, doi:10.1029/2011GL050582.

Collins, M., and Coauthors, 2013: Long-term climate change: Projections, commitments and irreversibility. Climate Change 2013: The Physical Science Basis, T. F. Stocker et al., Eds., Cambridge University Press, 1029-1136.

England, M. H., and Coauthors, 2014: Recent intensification of wind-driven circulation in the Pacific and the ongoing warming hiatus. Nat. Climate Change, 4, 222-227, doi:10.1038/ nclimate2106.

Flannigan, M. D., B. J. Stocks, and B. M. Wotton, 2000: Climate change and forest fires. Sci. Total Environ., 262, 221-229, doi:10.1016/S0048-9697(00)00524-6.

Frey, K. E., and L. C. Smith, 2007: How well do we know northern land cover? Comparison of four global vegetation and wetland products with a new ground-truth database for West Siberia. Global Biogeochem. Cycles, 21, GB1016, doi:10.1029/ 2006GB002706.

Friedl, M. A., D. Sulla-Menashe, B. Tan, A. Schneider, N. Ramankutty, A. Sibley, and X. Huang, 2010: MODIS 
collection 5 global land cover: Algorithm refinements and characterization of new datasets. Remote Sens. Environ., 114, 168-182, doi:10.1016/j.rse.2009.08.016.

Giri, C., Z. Zhu, and B. Reed, 2005: A comparative analysis of the Global Land Cover 2000 and MODIS land cover data sets. Remote Sens. Environ., 94, 123-132, doi:10.1016/ j.rse.2004.09.005.

Guan, X., J. Huang, R. Guo, and P. Lin, 2015a: The role of dynamically induced variability in the recent warming trend slowdown over the Northern Hemisphere. Sci. Rep., 5, 12669, doi:10.1038/srep12669.

$-,-, \ldots, \ldots$, and Y. Zhang, 2015b: Role of radiatively forced temperature changes in enhanced semi-arid warming over East Asia. Atmos. Chem. Phys., 15, 13777-13786, doi:10.5194/acp-15-13777-2015.

Hansen, M. C., and Coauthors, 2013: High-resolution global maps of 21st-century forest cover change. Science, 342, 850-853, doi:10.1126/science. 1244693 .

Harris, I., P. D. Jones, T. J. Osborn, and D. H. Lister, 2014: Updated high-resolution grids of monthly climatic observationsThe CRU TS3.10 dataset. Int. J. Climatol., 34, 623-642, doi:10.1002/joc.3711.

He, Y., J. Huang, and M. Ji, 2014: Impact of land-sea thermal contrast on interdecadal variation in circulation and blocking. Climate Dyn., 43, 3267-3279, doi:10.1007/s00382-014-2103-y.

Huang, J., X. Guan, and F. Ji, 2012: Enhanced cold-season warming in semi-arid regions. Atmos. Chem. Phys., 12, 5391-5398, doi:10.5194/acp-12-5391-2012.

—_, M. Ji, Y. Xie, S. Wang, Y. He, and J. Ran, 2015a: Global semi-arid climate change over last 60 years. Climate Dyn., $\mathbf{4 6}$, 1131-1150, doi:10.1007/s00382-015-2636-8.

— , H. Yu, X. Guan, G. Wang, and R. Guo, 2015b: Accelerated dryland expansion under climate change. Nat. Climate Change, 6, 166-171, doi:10.1038/nclimate2837.

Jensen, J. R., 2015: Introductory Digital Image Processing: A Remote Sensing Perspective. 4th ed. Prentice Hall Press, 544 pp.

Ji, F., Z. Wu, J. Huang, and E. P. Chassignet, 2014: Evolution of land surface air temperature trend. Nat. Climate Change, $\mathbf{4}$, 462-466, doi:10.1038/nclimate2223.

Jones, P. D., 2016: The reliability of global and hemispheric surface temperature records. Adv. Atmos. Sci., 33, 269-282, doi:10.1007/ s00376-015-5194-4.

Karl, T. R., and Coauthors, 2015: Possible artifacts of data biases in the recent global surface warming hiatus. Science, 348, 14691472, doi:10.1126/science.aaa5632.

Kharuk, V. I., A. M. Alshansky, and V. V. Yegorov, 1992: Spectral characteristics of vegetation cover: Factors of variability. Int. J. Remote Sens., 13, 3263-3272, doi:10.1080/ 01431169208904117.

—_, M. L. Dvinskaya, and K. J. Ranson, 2005a: The spatiotemporal pattern of fires in northern taiga larch forests of central Siberia. Russ. J. Ecol., 36, 302-311, doi:10.1007/ s11184-005-0077-z.

,,,--- and S. T. Im, 2005b: Expansion of evergreen conifers to the larch-dominated zone and climatic trends. Russ. J. Ecol., 36, 164-170, doi:10.1007/s11184-005-0055-5.

— , K. J. Ranson, and M. L. Dvinskaya, 2007: Evidence of evergreen conifer invasion into larch dominated forests during recent decades in central Siberia. Eurasian J. For. Res., 10, 163-171.

Kosaka, Y., and S.-P. Xie, 2013: Recent global-warming hiatus tied to equatorial Pacific surface cooling. Nature, 501, 403-407, doi:10.1038/nature12534.
Kullman, L., 2007: Tree line population monitoring of Pinus sylvestris in the Swedish Scandes, 1973-2005: Implications for tree line theory and climate change ecology. J. Ecol., 95, 41-52, doi:10.1111/j.1365-2745.2006.01190.x.

Lenton, T. M., H. Held, E. Kriegler, J. W. Hall, W. Lucht, S. Rahmstorf, and H. J. Schellnhuber, 2008: Tipping elements in the Earth's climate system. Proc. Natl. Acad. Sci. USA, 105, 1786-1793, doi:10.1073/pnas.0705414105.

Li, C., B. Stevens, and J. Marotzke, 2015: Eurasian winter cooling in the warming hiatus of 1998-2012. Geophys. Res. Lett., 42, 8131-8139, doi:10.1002/2015GL065327.

Li, J., C. Sun, and F. F. Jin, 2013: NAO implicated as a predictor of Northern Hemisphere mean temperature multidecadal variability. Geophys. Res. Lett., 40, 5497-5502, doi:10.1002/ 2013 GL057877.

MacDougall, A. H., C. A. Avis, and A. J. Weaver, 2012: Significant contribution to climate warming from the permafrost carbon feedback. Nat. Geosci., 5, 719-721, doi:10.1038/ngeo1573.

Meehl, G. A., J. M. Arblaster, J. T. Fasullo, A. Hu, and K. E. Trenberth, 2011: Model-based evidence of deep-ocean heat uptake during surface-temperature hiatus periods. Nat. Climate Change, 1, 360-364, doi:10.1038/nclimate1229.

_, H. Teng, and J. M. Arblaster, 2014: Climate model simulations of the observed early-2000s hiatus of global warming. Nat. Climate Change, 4, 898-902, doi:10.1038/nclimate2357.

NCDC, 2005a: TD-9290c-1 Global Synoptic Climatology Network C: The former USSR, version 1.0. [Available from National Centers for Environmental Information, 151 Patton Ave, Asheville, NC 28801.]

— 2005b: TD-9813 daily and sub-daily precipitation for the former USSR, version 1.0. [Available from National Centers for Environmental Information, 151 Patton Ave, Asheville, NC 28801.]

Ottlé, C., J. Lescure, F. Maignan, B. Poulter, T. Wang, and N. Delbart, 2013: Use of various remote sensing land cover products for plant functional type mapping over Siberia. Earth Syst. Sci. Data, 5, 331-348, doi:10.5194/essd-5-331-2013.

Pflugmacher, D., and Coauthors, 2011: Comparison and assessment of coarse resolution land cover maps for northern Eurasia. Remote Sens. Environ., 115, 3539-3553, doi:10.1016/ j.rse.2011.08.016.

Piao, S., P. Friedlingstein, P. Ciais, N. Viovy, and J. Demarty, 2007: Growing season extension and its impact on terrestrial carbon cycle in the Northern Hemisphere over the past 2 decades. Global Biogeochem. Cycles, 21, GB3018, doi:10.1029/2006GB002888.

Prentice, I. C., and Coauthors, 2007: Dynamic global vegetation modeling: Quantifying terrestrial ecosystem responses to large-scale environmental change. Terrestrial Ecosystems in a Changing World, J. Canadell, D. Pataki, and L. Pitelka, Eds., Springer, 175-192.

Rajaratnam, B., J. Romano, M. Tsiang, and N. S. Diffenbaugh, 2015: Debunking the climate hiatus. Climatic Change, 133, 129-140, doi:10.1007/s10584-015-1495-y.

Roberts, C. D., M. D. Palmer, D. McNeall, and M. Collins, 2015: Quantifying the likelihood of a continued hiatus in global warming. Nat. Climate Change, 5, 337-342, doi:10.1038/nclimate2531.

Roy, D. P., L. Boschetti, C. O. Justice, and J. Ju, 2008: The collection 5 MODIS burned area product: Global evaluation by comparison with the MODIS active fire product. Remote Sens. Environ., 112, 3690-3707, doi:10.1016/j.rse.2008.05.013.

Schwartz, M. D., R. Ahas, and A. Aasa, 2006: Onset of spring starting earlier across the Northern Hemisphere. Global Change Biol., 12, 343-351, doi:10.1111/j.1365-2486.2005.01097.x. 
Shugart, H. H., W. R. Emanuel, D. C. West, and D. L. DeAngelis, 1980: Environmental gradients in a simulation model of a beech-yellow-poplar stand. Math. Biosci., 50, 163-170, doi:10.1016/0025-5564(80)90034-6.

_, G. P. Asner, R. Fischer, A. Huth, N. Knapp, T. Le Toan, and J. K. Shuman, 2015: Computer and remote-sensing infrastructure to enhance large-scale testing of individual-based forest models. Front. Ecol. Environ., 13, 503-511, doi:10.1890/140327.

Shuman, J. K., H. H. Shugart, and T. L. O'Halloran, 2011: Sensitivity of Siberian larch forests to climate change. Global Change Biol., 17, 2370-2384, doi:10.1111/j.1365-2486.2011.02417.x.

— _ _ , and O. N. Krankina, 2014: Testing individual-based models of forest dynamics: Issues and an example from the boreal forests of Russia. Ecol. Modell., 293, 102-110, doi:10.1016/j.ecolmodel.2013.10.028.

— , N. M. Tchebakova, E. I. Parfenova, A. J. Soja, H. H. Shugart, D. Ershov, and K. Holcomb, 2015: Forest forecasting with vegetation models across Russia. Can. J. For. Res., 45, 175184, doi:10.1139/cjfr-2014-0138.

Smith, B., I. C. Prentice, and M. T. Sykes, 2001: Representation of vegetation dynamics in the modelling of terrestrial ecosystems: Comparing two contrasting approaches within European climate space. Global Ecol. Biogeogr., 10, 621-637, doi:10.1046/j.1466-822X.2001.00256.x.

Steinman, B. A., M. E. Mann, and S. K. Miller, 2015: Atlantic and Pacific multidecadal oscillations and Northern Hemisphere temperatures. Science, 347, 988-991, doi:10.1126/science.1257856.

Tchebakova, N. M., E. Parfenova, and A. J. Soja, 2009: The effects of climate, permafrost and fire on vegetation change in Siberia in a changing climate. Environ. Res. Lett., 4, 045013, doi:10.1088/1748-9326/4/4/045013.

Townshend, J. R. G., M. Carroll, C. Dimiceli, R. Sohlberg, M. Hansen, and R. DeFries, 2011: Vegetation continuous fields MOD44B, 2001 percent tree cover, collection 5. University of Maryland/NASA Global Land Cover Facility, accessed July 2013. [Available online at http://glcf.umd.edu/data/vcf/.]

Trenberth, K. E., and J. T. Fasullo, 2013: An apparent hiatus in global warming? Earth's Future, 1, 19-32, doi:10.1002/2013EF000165.

Tung, K.-K., and J. Zhou, 2013: Using data to attribute episodes of warming and cooling in instrumental records. Proc. Natl. Acad. Sci. USA, 110, 2058-2063, doi:10.1073/pnas.1212471110.

Van Der Werf, G. R., and Coauthors, 2010: Global fire emissions and the contribution of deforestation, savanna, forest, agricultural, and peat fires (1997-2009). Atmos. Chem. Phys., 10, 11 707-11 735, doi:10.5194/acp-10-11707-2010.

Wallace, J. M., Q. Fu, B. V. Smoliak, P. Lin, and C. M. Johanson, 2012: Simulated versus observed patterns of warming over the extratropical Northern Hemisphere continents during the cold season. Proc. Natl. Acad. Sci. USA, 109, 14337-14342, doi:10.1073/pnas.1204875109.

Wang, S., J. Huang, Y. He, and Y. Guan, 2014: Combined effects of the Pacific decadal oscillation and El Niño-Southern Oscillation on global land dry-wet changes. Sci. Rep., 4, 6651, doi:10.1038/srep06651.

Yan, X., and H. H. Shugart, 2005: FAREAST: A forest gap model to simulate dynamics and patterns of eastern Eurasian forests. J. Biogeogr., 32, 1641-1658, doi:10.1111/ j.1365-2699.2005.01293.x. 